\title{
Semi-empirical predictive equations for the initial amplitude of submarine landslide-generated waves: applications to 1994 Skagway and 1998 Papua New Guinea tsunamis
}

\author{
Ramtin Sabeti $^{1}$ (D) $\cdot$ Mohammad Heidarzadeh $^{1}$
}

Received: 17 February 2020 / Accepted: 6 May 2020 / Published online: 21 May 2020

(c) The Author(s) 2020

\begin{abstract}
Accurate predictions of maximum initial wave amplitude are essential for coastal impact assessment of tsunami waves generated by submarine landslides. Here, we analyse the existing predictive equations for the maximum initial amplitude $\left(\eta_{\max }\right)$ of submarine landslide-generated waves and study their performance in reproducing real-world landslide incidents. Existing equations include various landslide parameters such as specific gravity $\left(\gamma_{s}\right)$, initial submergence $(d)$, slide length $(B)$, width $(w)$, thickness $(T)$ and slope angle $(\theta)$. To determine how landslide parameters affect wave amplitude, we conduct a systematic sensitivity analysis. Results indicate that the slide volume $(V=B \times w \times T)$ and $d$ are among the most sensitive parameters. The data from the 1994 Skagway (observed $\eta_{\max }: 1.0-2.0 \mathrm{~m}$ ) and 1998 Papua New Guinea (PNG) (observed $\eta_{\max }: 10-16 \mathrm{~m}$ ) incidents provided valuable benchmarks for evaluating the performance of the existing equations. The predicted maximum initial amplitudes of 0.03-686.5 $\mathrm{m}$ and 3.7-6746.0 $\mathrm{m}$ were obtained for the 1994 and 1998 events, respectively, indicating a wide range for wave amplitudes. The predicted estimates for the smaller-sized event, i.e. the 1994 Skagway, appear to be more accurate than those made for the larger event, i.e. the 1998 PNG case. We develop a new predictive equation by fitting an equation to actual submarine landslide tsunamis: $\eta_{\max }=50.67\left(\frac{V}{d}\right)^{0.34}$, where $V$ is the slide volume $\left(\mathrm{km}^{3}\right), d$ is initial submergence depth (m), and $\eta_{\max }$ is in metres. Our new equation gives wave amplitudes of $1.6 \mathrm{~m}$ and $7.8 \mathrm{~m}$ for the 1994 and 1998 landslide tsunamis, respectively, which are fairly consistent with real observations.
\end{abstract}

Keywords Landslide $\cdot$ Landslide-generated waves · Tsunami · Papua New Guinea

Ramtin Sabeti

ramtin.sabeti@brunel.ac.uk

1 Department of Civil and Environmental Engineering, Brunel University London, Uxbridge UB8 3PH, UK 


\section{Introduction}

Landslide-generated waves have been major threats to coastal areas and have led to destruction and casualties in several locations. In July 1998, a landslide tsunami in Sissano Lagoon, Papua New Guinea, generated a 15-m high wall of water (Fig. 1c) killing more than 2100 people (Tappin et al. 2008; Synolakis et al. 2002; Lynett et al. 2003; Heidarzadeh and Satake 2015). It is now well accepted that the source of the 1998 PNG tsunami was a combined earthquake-landslide source (Fig. 1a, b). The 1994 Skagway, Alaska (USA) landslide tsunami destroyed the railway dock; as a result, a construction worker was killed and the harbour was damaged (Kulikov et al. 1996; Rabinovich et al. 1999) (Fig. 1d-f). Another significant landslide tsunami was generated in Nice (France) airport on 16 October 1979 where a part of the new harbour extension, nearby to the Nice international airport, slumped into the Mediterranean Sea (Assier-Rzadkieaicz et al. 2000; Dan

\section{PNG tsunami}

(a)

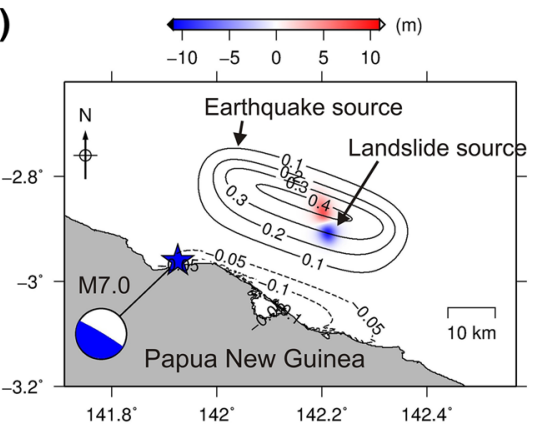

(b)
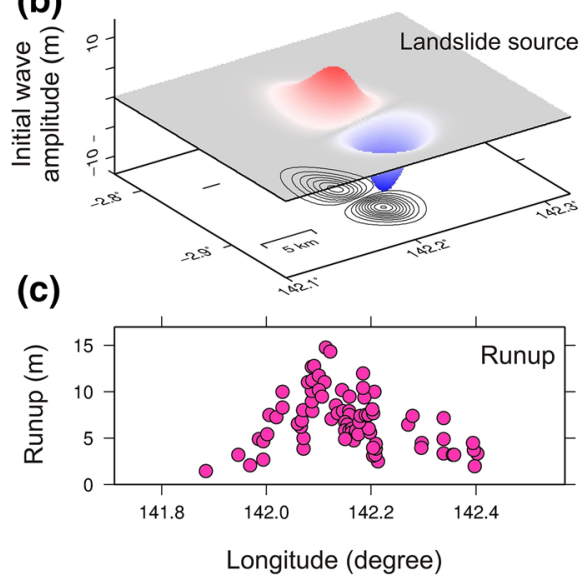

\section{Skagway tsunami}

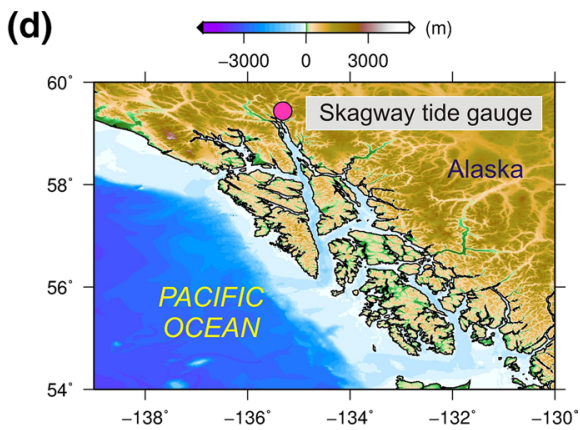

(e)

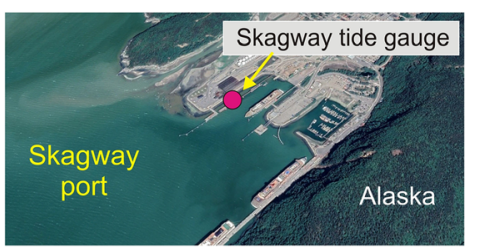

(f)

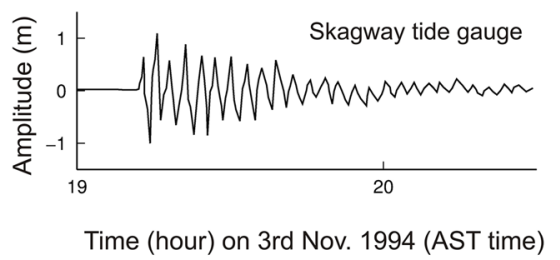

Fig. 1 a The combined landslide (colour map) and earthquake (contour) source of the 1998 PNG tsunami based on Heidarzadeh and Satake (2015). b The 3D projection of the landslide source of the 1998 PNG tsunami. c The distribution of the surveyed tsunami run-up during the 1998 PNG event based on the data from Synolakis et al. (2002). d Location map showing the Skagway tide gauge position, which recorded the 1994 Skagway landslide tsunami. e Google-Earth image showing the Skagway harbour. f The tide gauge waveform of the 1994 Skagway tsunami digitized from Rabinovich et al. (1999). AST on the label of the horizontal axis is abbreviation for Atlantic Standard Time. Panels a-b are modified from Heidarzadeh and Satake (2015) 
et al. 2007). The $2-3 \mathrm{~m}$ high tsunami swept away 11 people and left one death (Gennesseaux 1980; Sultan et al. 2004; Fine et al. 2005). Other major landslide events are 1946 Unimak (Alaska) (Okal et al. 2003), Storegga (approximately 8,100 years ago) (Harbitz 1992), 1741 Oshima-Oshima (Japan) (Satake and Kato 2001) and 1999 Izmit bay (Turkey) (Yalciner et al. 1999) tsunamis.

Due to the importance of landslide tsunamis for coastal safety, various studies have been conducted to characterize the waves generated by submarine failures, including experimental, numerical and analytical studies. These investigations over the past years have shed light on the processes of generation and propagation of landslide-generated waves. Wiegel (1955) was a pioneer in physical modelling of water waves generated by submarine landslides, who has been inspired by many researchers after his work. Fundamentals of landslide tsunami characteristics were discovered by Wiegel (1955) as he reported that the leading wave amplitude of landslide tsunamis increases by increasing block density; by decreasing initial block submergence; and by increasing incline angle. Harbitz and Pedersen (1992) presented analytical solutions for wave excitation by submarine landslides in order to study the influence of governing parameters. Harbitz and Pedersen (1992) found an expression for the relative importance of the effect of landslide volume versus the shear stress on the interface between fluid and sliding masses. In terms of numerical simulations, the research by Heinrich (1992) replicated the effect of water waves created by a submarine solid block descending a sloping beach in a wave flume by a standard finite difference technique. Likewise, Liu et al. (2005) presented a numerical model for landslide tsunami based on large eddy simulations technique validated by a set of large-scale experimental studies. Heidarzadeh et al. (2014) reviewed the existing numerical tools for modelling landslidegenerated waves.

A number of researchers have proposed empirical equations for the prediction of maximum initial landslide tsunami amplitude. However, it is essential to examine how accurately these equations can reproduce actual landslide events. Here, we study the performance of the existing empirical and semi-empirical equations for the prediction of landslide tsunami amplitudes. Empirical equations are beneficial for predicting the amplitudes of landslide-generated waves in a timely way and can be readily employed for preliminary hazard analysis. The maximum initial amplitude of landslide waves around the source region is considered as the key performance indicator in this research. This parameter is difficult to measure directly; but it is available through experimental and numerical studies for some of the landslide events, as discussed later in this article. We study the existing equations and examine their performance by reproducing two actual landslide tsunami events for which real measurements are available: the 1994 Skagway and the 1998 PNG events. Finally, we propose a new empirical equation for prediction of maximum initial amplitude of landslide tsunamis based on data from actual events.

\section{Methodology and data}

The initial landslide-generated wave features are strongly influenced by landslide kinematics. Hence, determining the slide law of motion is necessary. Most landslide tsunami studies have employed the kinematic equations developed by Watts et al. (2005) for slide motion; here, we benefit from the same equations. The characteristic length $\left(s_{0}\right)$ and characteristic time $\left(t_{0}\right)$ for slide kinematics are defined as follows: 


$$
\begin{aligned}
& s_{0}=\frac{u_{t}^{2}}{a_{0}} \\
& t_{0}=\frac{u_{t}}{a_{0}}
\end{aligned}
$$

where $u_{t}$ is terminal velocity and $a_{0}$ is the initial acceleration of the sliding mass.

We study the existing predictive equations for $2 \mathrm{D}$ (in section) characteristic tsunami amplitude generated by submarine landslides. The term characteristic amplitude refers to the maximum initial tsunami amplitude ( $\eta_{\max }$ in Fig. 2). To find the effect of each landslide parameter (i.e. length, width, thickness, slope angle, initial slide submergence depth and slide specific gravity; Fig. 2) on the maximum initial wave amplitude, sensitivity analyses were conducted. We plotted the predicted wave amplitudes against single parameters in 2D plots (i.e. the wave amplitude versus each landslide parameter) and a combination of two parameters in 3D plots (e.g. the wave amplitude versus length of slide and slope angle). The mathematical toolbox of MATLAB (version: R2018a; Mathworks 2019) was used for our $2 \mathrm{D}$ and $3 \mathrm{D}$ analyses.

In the next stage, we evaluate the performance of the predictive equations by using them to reproduce the maximum initial wave amplitudes of two case studies, the 1994 Skagway and 1998 PNG, and compare the predicted values with the real available measurements for both events. The measured data from two tsunamis provide a valuable benchmark for evaluating the performance of different predictive equations. However, considering the different values reported for the initial landslide parameters in the literature, we used a sensible range for each landslide parameter.

We develop a new predictive equation for estimating the maximum initial wave amplitude by fitting an equation to the actual data from landslide tsunami incidents. The linear regression methodology is applied for deriving the new equation, which is the most widely used statistical technique for estimating cause-effect relationships (Iquebal and Himadri 2012). Our linear regression was performed through the stochastic optimization technique of genetic algorithm (GA) (Mathworks 2019). The GA Toolbox employs a cost function

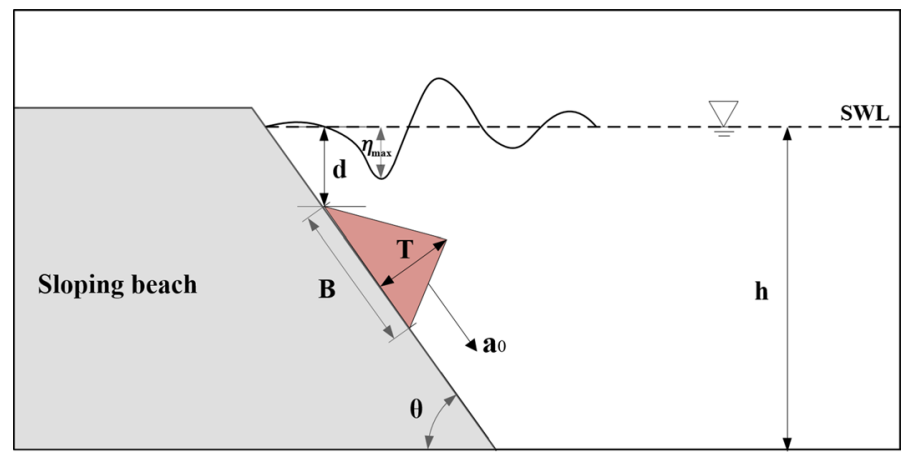

Fig. 2 Schematic definition of the geometrical and kinematic parameters of a submarine landslide. SWL stands for still water level. Displayed parameters: $\eta_{\max }$ is wave zero-to-trough (or zero-to-crest) amplitude; $B$ is the slide length; $d$ is the initial slide submergence depth; $\theta$ is slope angle; $a_{0}$ is the initial acceleration of the slide; $h$ is the water depth; and $T$ is the slide thickness 
to build a set of versatile routines for implementing a wide range of genetic algorithm methods.

Table 1 provides the data for the landslide parameters of each event based on the existing literature including slide specific gravity $\left(\gamma_{s}\right)$, initial slide submergence $(d)$, slide length $(B)$, width $(w)$, thickness $(T)$ and slope angle $(\theta)$. A representative value for each landslide parameter was defined, which is the most likely value for each parameter (Table 1); these representative values were used to reproduce a corresponding wave amplitude by the predictive equations rather than a range of amplitude given by the parameter range. To reproduce the highest and the lowest possible wave amplitudes using the proposed equations, we considered all combinations of the ranges of the initial landslide parameters. For this, the 'ndgrid' function in MATLAB (Mathworks 2019) was employed to transform the specified domain for six landslide parameters into arrays, which is ultimately used as inputs for the existing predictive equations.

\section{Existing predictive equations}

Several equations have been proposed for the prediction of the maximum initial wave amplitude ( $\eta_{\text {max }}$; Fig. 2$)$ generated by submarine landslides. Table 2 lists seven such predictive equations. The equations by Watts et al. (1998, 2003, 2005) and Jilani and AtaieAshtiani (2008) benefit from the following fundamental relationships for terminal velocity $\left(u_{t}\right)$ and initial acceleration $\left(a_{0}\right)$ of landslides:

$$
\begin{gathered}
u_{t}=\sqrt{g B} \sqrt{\frac{\pi\left(\gamma_{s}-1\right) \sin \theta}{2 C_{d}}} \\
a_{0}=g \frac{\gamma_{s}-1}{\gamma_{s}+C_{m}} \sin \theta
\end{gathered}
$$

where $B$ is slide length, $C_{d}$ is the drag coefficient, $\theta$ is the angle of the slope, $\gamma_{s}$ is the slide specific gravity, $g$ is gravitational acceleration, and $C_{m}$ is the added mass coefficient. In this study, we assumed no deformation for the sliding mass; consequently, the shape-related

Table 1 Initial landslide parameters and representative values for the 1994 Skagway and 1998 PNG landslide tsunamis

\begin{tabular}{lll}
\hline Parameter $^{*}$ & 1994 Skagway; range (representative value) & 1998 PNG; range (representative value) \\
\hline$T(\mathrm{~m})$ & $10-20(15)$ & $500-900(760)$ \\
$B(\mathrm{~m})$ & $100-600(350)$ & $3000-7000(4500)$ \\
$w(\mathrm{~m})$ & $330-390(360)$ & $3000-7000(5000)$ \\
$d(\mathrm{~m})$ & $26-155(88)$ & $1000-2000(1500)$ \\
$\gamma_{s}$ & $1.75-1.85(1.8)$ & $1.9-2.2(2.15)$ \\
$\theta\left(^{\circ}\right)$ & $9-26(17.5)$ & $5-15(8)$ \\
Reference & Campbell (1995), Kulikov et al. (1996), Watts & Heinrich et al. (2001), Synolakis et al. \\
& et al. (2003), Campbell and Nottingham & $(2002)$, Heidarzadeh and Satake \\
& $(1999)$ & $(2015)$ \\
\hline
\end{tabular}

${ }^{*} T$, slide thickness; $B$, slide length; $w$, slide width; $d$, initial submergence depth; $\gamma_{s}$ is the specific gravity of slide material; $\theta$ slope angle 
Table 2 Existing predictive equations for estimating the maximum initial wave amplitude of submarine landslides

\begin{tabular}{|c|c|c|c|}
\hline Author $^{\mathrm{a}}$ & Equation $^{\mathrm{b}}$ & Approach & Range of validity \\
\hline \multirow[t]{2}{*}{ HRB-92 } & $\eta_{\max }=\frac{\tau t_{r}}{2 \rho C_{0}}$ & $\begin{array}{r}\text { Analytical- } \\
\text { numerical }\end{array}$ & $X_{f}<x-B-C_{0}$ \\
\hline & $\eta_{\max }=\frac{\tau B}{2 \rho C_{0}^{2}\left|1-F_{r}\right|}$ & $\begin{array}{r}\text { Analytical- } \\
\text { numerical }\end{array}$ & $X_{f}>B$ \\
\hline \multirow[t]{2}{*}{ WTS-98 } & $\eta_{\max }=\frac{0.33 S_{0}}{\left(\frac{u_{t} \sqrt{g d}}{a_{0} B}\right)^{2.01}}$ & Experimental & $\begin{array}{l}\theta=45^{\circ} \\
d / B \approx 0.87\end{array}$ \\
\hline & & & $3<\frac{u_{t} \sqrt{g d}}{a_{0} B}<4.5$ \\
\hline GRL- $02^{c}$ & $\eta_{\max }=0.217+\left(3.83 \frac{w}{B}\right)-0.632\left(\frac{w}{B}\right)^{2}$ & Numerical & N/A \\
\hline MRT-03 & $\eta_{\max }=0.3945 \mathrm{~V}$ & $\begin{array}{l}\text { Regression to real } \\
\text { events data }\end{array}$ & N/A \\
\hline WTS-03 & $\eta_{\max }=0.2193 T\left(1-0.754 \sin \theta+0.1704 \sin _{\theta}^{2}\right)\left(\frac{B \sin _{\theta}^{2}}{d}\right)$ & Experimental & N/A \\
\hline WTS-05 & $\eta_{\max }=S_{0}(0.05741-0.0431 \sin \theta)+\left(\frac{T}{B}\right)\left(\frac{B \sin \theta}{d}\right)^{1.25}$ & Experimental & $\begin{array}{l}\theta \in[5,30]^{\circ} \\
d / d_{\text {ref }} \in[0.06,3] \\
T / B \in[0.008,0.2]\end{array}$ \\
\hline JIL-07 & $\eta_{\max }=S_{0} f_{1}\left(\frac{T}{B}, \theta\right)\left(\frac{d}{B}\right)^{f_{2}\left(\frac{T}{B}, \theta\right)}$ & Experimental & $\begin{array}{l}\theta \in[5,60]^{\circ} \\
d / B \in[0,1.5] \\
T / B \in[0.00625,1]\end{array}$ \\
\hline
\end{tabular}

${ }^{a}$ Abbreviations are: Harbitz and Pedersen (1992), HRB-92; Watts (1998), WTS-98; Grilli et al. (2002), GRL-02; Murty (2003), MRT-03; Watts et al. (2003), WTS-03; Watts et al. (2005), WTS-05; Jilani and Ataie-Ashtiani (2008), JIL-07. ${ }^{\mathrm{b}} \eta_{\max }$ is wave zero-to-trough (or zero-to-crest) amplitude, $B$ and w are the slide length and width; $d$ is the initial slide submergence; $V$ is the volume of slide (for MRT-03 equation, the input value for $V$ must be in $\left.10^{6} \mathrm{~m}^{3}\right) ; \theta$ is the angle of the slope; $\gamma_{w}$ is the specific gravity of water; $\tau$ is shear stress; $t_{0}$ is the characteristic time of landslide motion; $C_{0}$ is the wave speed; $u_{t}$ is terminal velocity; $a_{0}$ is the initial acceleration; $S_{0}$ is initial distance of landside acceleration; $d_{\text {ref }}=B \sin \theta$ is reference thickness; $X_{f}$ is the shifted distance of two families of free waves; $t_{r}$ is running time of slide and $F_{r}$ is Froude number; $f_{1}$ and $f_{2}$ are functions of $T, B$ and $\theta$ (see Eqs. 4-6 in Jilani and Ataie-Ashtiani 2008). ${ }^{\text {c}}:$ In this dimensionless equation, all values for $\eta, w$ and $B$ should be in metres

coefficient of the failing mass, i.e. the drag coefficient $\left(C_{d}\right)$ and the added mass coefficient $\left(C_{m}\right)$, are constant and assumed to have the value of $1 . C_{m}$ is a nondimensional parameter that depends on the initial submergence depth $(d)$ and the slope angle $(\theta) . C_{d}$ is a function of the shape of the sliding mass and the slope angle $(\theta)$. We note that the type of the sliding mass, either a solid block or a deforming material, affects the characteristics of the generated waves (Watts et al. 2005). Based on the research by Grilli and Watts (2005), the maximum initial wave is larger for deformable slides in comparison to solid block failures.

Table 2 reveals that these equations have been developed employing different approaches such as experimental, analytical and numerical methods. Some equations require two/three initial landslide parameters for predicting the maximum initial wave amplitude such as those by Murty (2003) and Grilli et al. (2002), whereas other equations use five/six initial landslide parameters; e.g. those by Watts et al. (2005) and Jilani and Ataie-Ashtiani (2008). Except for the equations by Murty (2003) and Grilli et al. (2002), the other five equations directly or indirectly include six landslide parameters: the slide specific gravity $\left(\gamma_{s}\right)$, the initial slide submergence $(d)$, length of the slide $(B)$, width of the slide $(w)$, thickness of the slide $(T)$ and angle of the slope $(\theta)$. According to Table 2, the slide length $(B)$ and thickness $(T)$ appear in most equations. We note that slide width $(w)$ is taken as a unit since many of 
these equations are developed for 2D-in-section cases; thus, slide width is hidden in the equations. This indicates the importance of slide volume $(V=B \times w \times T)$ for the prediction of the maximum initial tsunami amplitudes generated by submarine landslides. It is noted that equations with a small number of initial landslide parameters (e.g. Murty 2003) could be helpful when only minimum information is available for a particular event.

As the wavelengths of landslide-generated waves are shorter compared to earthquakegenerated waves, they show greater dispersive effects (Watts et al. 2005; Heidarzadeh et al. 2014, 2020; Yalciner et al. 2014). While the phase velocity (c) of long oceanic waves (representing earthquake tsunamis) takes the form of $c=\sqrt{g h}$, in which $h$ is water depth, it becomes $c=\sqrt{\frac{g L}{2 \pi}}$ for short waves (representing most landslide tsunamis) where $L$ is the wavelength indicating that $c$ is a function of $L$. Therefore, longer waves travel faster than shorter waves for landslide tsunamis, which causes wave dispersion. The three equations by WTS-98, -03 and -05 (see Table 2) account for the effects of dispersion through introduction of the Ursell parameter $(U)$ in their formulations:

$$
U=\frac{H L^{2}}{h^{3}}
$$

where $H$ is wave height and $h$ is water depth. The dispersion effect is also considered by HRB-92 (Table 2) by introducing a dispersion relation (see Eq. 25 in Harbitz and Pedersen $1992)$ in their equations.

\section{Sensitivity analysis}

In order to determine how different values of landslide parameters affect wave amplitude, we conducted a series of sensitivity analyses. Figures 3 and 4 present the results of the sensitivity analyses for single landslide parameters. Regarding the slide length (B) (Fig. 3a), it can be seen that all equations show a direct linear relationship between slide length and tsunami amplitude. For slide length in the range of 400-900 m, wave amplitudes predicted by most equations are up to $20 \mathrm{~m}$, whereas the equation by Watts (1998), WTS-98, predicts approximately three times larger tsunami amplitudes than MRT-03 and HRB-92. The sensitivity analysis for the initial slide submergence (d) (Fig. 3b) shows that a rise in submergence depth causes a reduction in wave amplitude in an exponential manner. The slide width ( $w$ ) and wave amplitude are directly related to each other (Fig. 3c). However, the amplitude predictions by Harbitz and Pedersen (1992), HRB-92, are constantly larger than those given by other equations. According to Fig. 3d, there is a direct linear relationship between slide specific gravity $\left(\gamma_{s}\right)$ and wave amplitude. Although the equations by WTS-05 and JIL-07 predict similar values, the equations by WTS-98 and HRB-92 deliver five and 10 times higher amplitudes, respectively.

Regarding the slide thickness $(T)$, although all proposed equations show a direct relationship between wave amplitude and slide thickness, JIL-07 provides larger amplitudes with an exponential curve. For example, for the slide thickness of $50 \mathrm{~m}$, the predicted amplitude varies in the range of 4.5-21.5 m (Fig. 4a). With regard to slope angle, Fig. 4b reveals contradictory behaviours in wave amplitude as slope angle changes: HRB-92 and WTS-98 indicate a direct linear relationship between slope angle and wave amplitude with gradually rising rates, whereas WTS-05 shows an increase in wave amplitude for $\theta=15-35^{\circ}$ in an exponential manner followed by amplitude decrease for $\theta=35-60^{\circ}$. As compared to WTS-05, JIL-07's equation behaves in an opposite manner. 
(a)

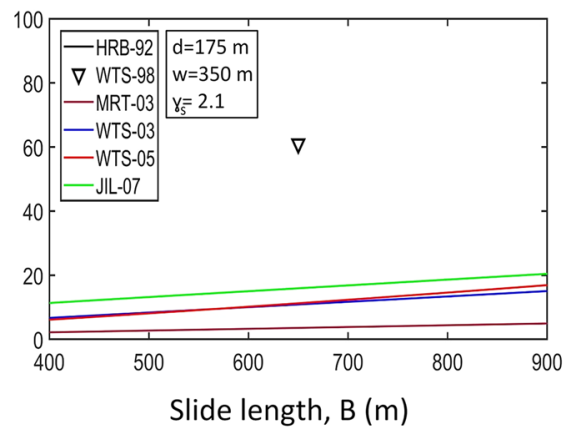

(c)

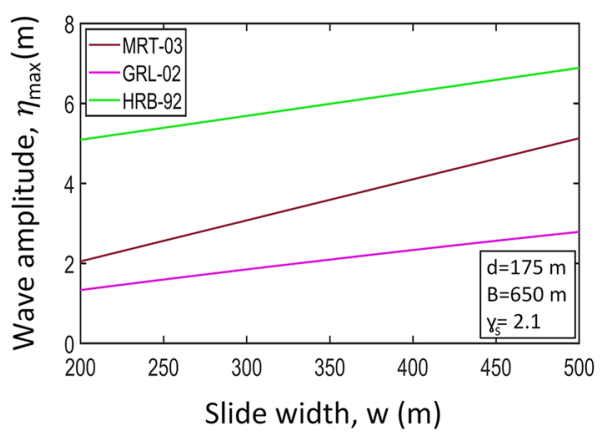

(b)

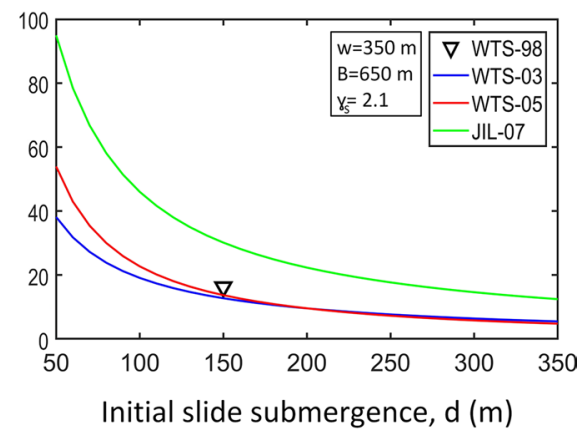

(d)

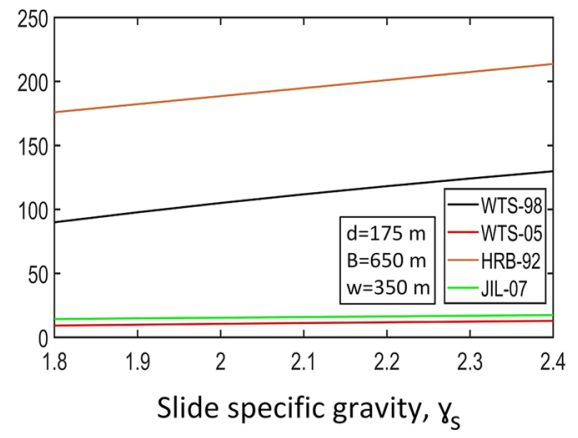

Fig. 3 Sensitivity of landslide wave amplitudes to slide parameters $B$ (slide length), $d$ (initial slide submergence), $w$ (slide width) and $\gamma_{s}$ (slide specific gravity). For all these panels, thickness and slope angle are fixed at $40 \mathrm{~m}$ and $22.5^{\circ}$, respectively. In each panel, while one slide parameter is varied, the other parameters are kept constant. The values of the constant slide parameters are shown in a box within each panel. Abbreviations are: Harbitz and Pedersen (1992), HRB-92; Watts (1998), WTS-98; Grilli et al. (2002), GRL-02; Murty (2003), MRT-03; Watts et al. (2003), WTS-03; Watts et al. (2005), WTS-05; Jilani and Ataie-Ashtiani (2008), JIL-07

Figures 5, 6 and 7 give the results of sensitivity analyses for two landslide parameters simultaneously. Based on Fig. 5, all the existing equations show that an increase in the slide length $(B)$ combined with a decrease in the initial slide submergence $(d)$ results in an increase in wave amplitude. However, these equations (i.e. WTS-98, WTS-03, WTS-05, and JIL-07) do not yield similar results. Given same ranges for initial landslide parameters, JIL-07 reaches a value of approximately $60 \mathrm{~m}$ for the maximum wave amplitude, while WTS-03 gives a value of approximately $12 \mathrm{~m}$. Figure 6 examines the effects of the slide length $(B)$ and the slope angle $(\theta)$ on wave amplitude. The results indicate that the equations by WTS-05, WTS-03 and HRB-92 produce an increase in wave amplitude by simultaneous increase in $B$ and $\theta$. For WTS-98, there are three limitations for its range of validity; one of the limitations implies that the slope angle must be 45 degrees; consequently, the effect of slope angle on wave amplitude is not given by WTS-98. A direct linear relationship between slide length and wave amplitude is seen for WTS-98. In contrast with other equations, JIL-07's equation behaves differently where an increase in slope angle results in a decrease in wave amplitude. The effects of specific gravity $\left(\gamma_{s}\right)$ and slide length $(B)$ on wave amplitude are illustrated in Fig. 7. An increase in the length and specific gravity 
(a)

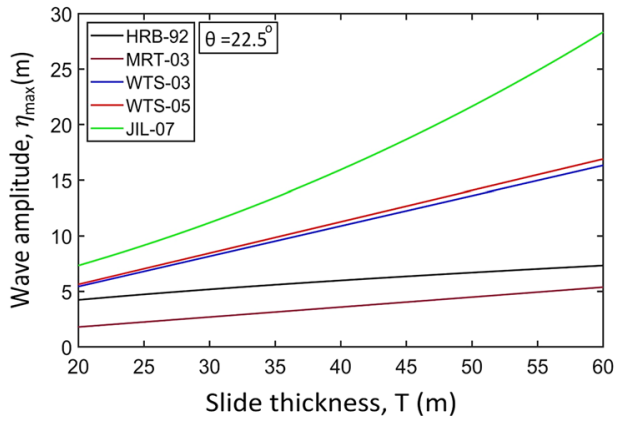

(b)

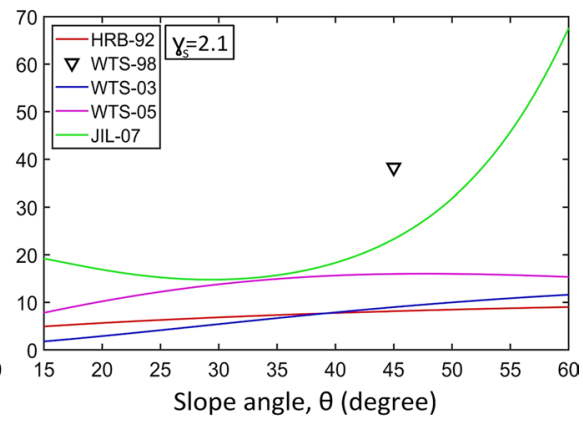

Fig. 4 Sensitivity of wave amplitudes to slide parameters $T$ (thickness) and $\theta$ (slope angle). For both panels, slide width, slide length and specific gravity are fixed at $350 \mathrm{~m}, 650 \mathrm{~m}$ and 2.1 , respectively. The initial submergence $(d)$ is $175 \mathrm{~m}$. In each panel, while one slide parameter is varied, the other parameters are kept constant. The values of the constant slide parameters are shown in a box within each panel. Abbreviations are: Harbitz and Pedersen (1992), HRB-92; Watts (1998), WTS-98; Grilli et al. (2002), GRL-02; Murty (2003), MRT-03; Watts et al. (2003), WTS-03; Watts et al. (2005), WTS-05; Jilani and Ataie-Ashtiani (2008), JIL-07

of the slide (i.e. $\gamma_{s}$ and $B$, respectively) is followed by an increase in the maximum wave amplitude (Fig. 7). Although three equations (i.e. WTS-98, WTS-05, and JIL-07) demonstrated similar behaviour, the maximum wave amplitudes are significantly different. The WTS-05 and JIL-07 equations predict maximum wave amplitudes of 15-30 m, whereas WTS-98 predicted a maximum wave amplitude of approximately $120 \mathrm{~m}$.

Overall, sensitivity analyses indicate that the slide volume $(V)$ and the initial slide submergence $(d)$ are among the most sensitive parameters on the maximum initial landslide wave amplitudes: higher slide lengths and lower initial slide submergence depths lead to higher wave amplitudes. Our study shows that the predictions made by different equations for the maximum initial landslide wave amplitudes vary in a wide range and are sometimes divided by one order of magnitude. This clearly highlights the need for further experimental and numerical studies on the subject.

\section{Performance to the 1994 Skagway and 1998 Papa New Guinea tsunamis}

The 1994 Skagway, Alaska landslide tsunami event, which destroyed $300 \mathrm{~m}$ of the railway and claimed the life of one construction worker, was applied as one of the benchmark events here. This event occurred at low tide, and no earthquake was reported at that time. A tide gauge belonging to the National Oceanic and Atmospheric Administration of the USA, located in Skagway harbour (see Fig. 1d, e), recorded approximately $1 \mathrm{~m}$ zero-to-crest wave amplitude with a wave period of $\sim 3$ min (Fig. 1f) (Kulikov et al. 1996). Watts et al. (2005) reported $2.1 \mathrm{~m}$ as the maximum initial wave amplitude. Therefore, we considered a range from 1 to $2.1 \mathrm{~m}$ as the observed initial wave amplitude for this event (Table 3, first row; Fig. 8a, pink lines). We employ the existing predictive equations (Table 2) to estimate the maximum amplitude of the initial landslide tsunami wave using the initial landslide parameters given in Table 1. The outcome is shown in Table 3 and Fig. 8a. In Table 3, the representative wave amplitudes correspond to the representative values for initial landslide 
(a)

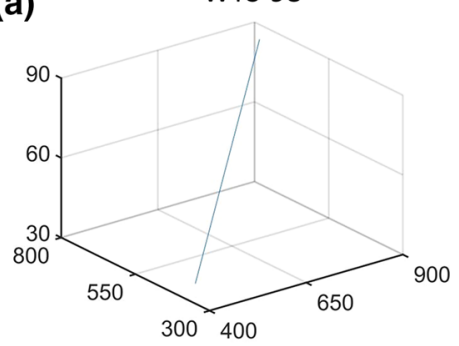

(b)

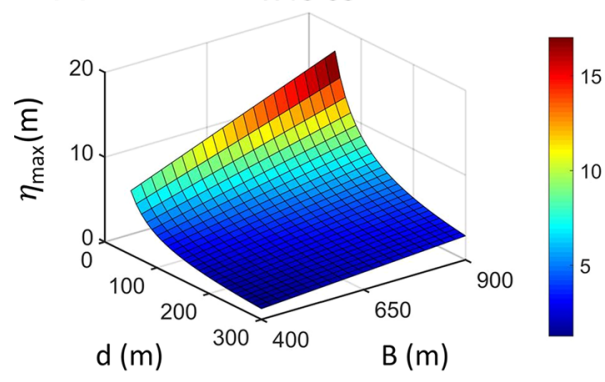

(c)

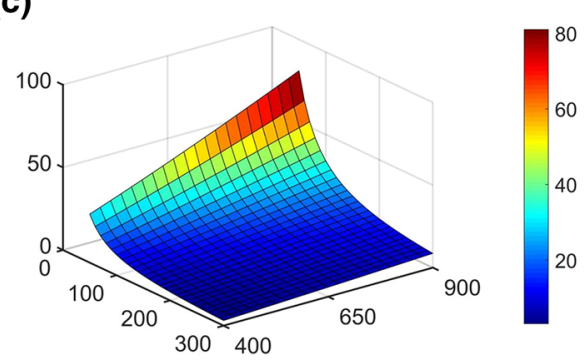

(d)

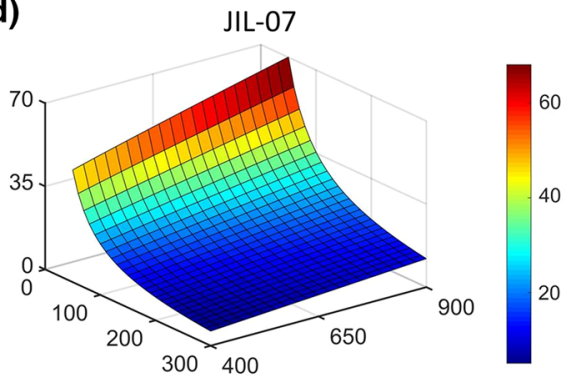

a) $\gamma_{s}=2.1 ; \theta=45.0^{\circ} ; d / b \approx 0.87$

b) $\gamma_{s}=n / a ; \theta=22.5^{\circ} ; T=40 \mathrm{~m}$

c) $\gamma_{5}=2.1 ; \quad \theta=22.5^{\circ} \quad T=40 \mathrm{~m}$

d) $x_{5}=2.1 ; \theta=22.5^{\circ} ; T=40 \mathrm{~m}$

Fig. 5 Performance of the equations by Watts (1998) (WTS-98), Watts et al. (2003) (WTS-03), Watts et al. (2005) (WTS-05) and Jilani and Ataie-Ashtiani (2008) (JIL-07) for the prediction of maximum initial landslide wave amplitudes. Two landslide parameters $(B$ and $d)$ are varied here. In each panel, while two slide parameters are varied, the other parameters are kept constant. The values of the constant slide parameters are shown at the bottom of the figure for each panel. For panel ' $b$ ', the parameter $\gamma_{s}$ does not exist in the equation by Watts et al. (2003); thus, we put 'n/a' here which stands for 'not applicable'

parameters (Table 1). The predicted values range from 0.03 to $686.5 \mathrm{~m}$ giving five orders of magnitude difference between the minimum and maximum predictions. In terms of representative wave amplitudes, the predictions are in the range of 0.8-19.4 $\mathrm{m}$ (Table 3, last column; Fig. 8a, yellow circles), whereas observed tsunami amplitude was 1.0-2.1 m. Most existing equations, except for WTS-98, fairly reproduce the observation (Fig. 8a).

The second case study is the tsunami that struck Papua New Guinea (PNG) in 1998 , where a moderate earthquake $\left(M_{w}=7\right)$ triggered a destructive landslide tsunami (Fig. 1a). The landslide-generated waves caused the destruction of three villages and the loss of more than 2100 people (Tappin et al. 2008; Heinrich et al. 2001; Synolakis et al. 2002). The tsunami was recorded on a few tide gauges in the far-field including stations of Lombrum (PNG), Rabaul (PNG), Malakal Island (Palau) and Yap Island (State of Yap) located $600-1450 \mathrm{~km}$ from the source, but no near-field tide gauge record is available (Heidarzadeh and Satake 2015). The tsunami recorded a maximum trough-to-crest wave height of 3-9 cm at the far-field tide gauges (Heidarzadeh and Satake 2015). In the near field, tsunami run-up was up to $15 \mathrm{~m}$ (Synolakis et al. 2002) (Fig. 1c). The 1998 PNG tsunami was a turning point in tsunami research since it showed that submarine 
(a)

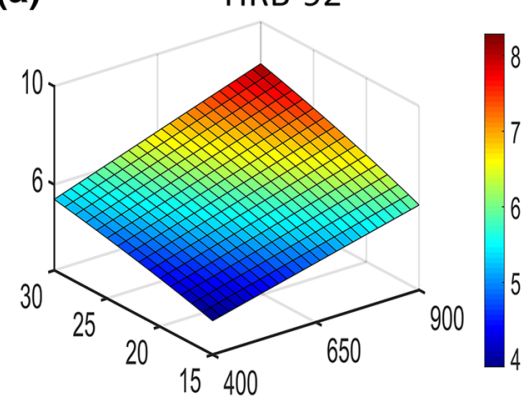

(b)

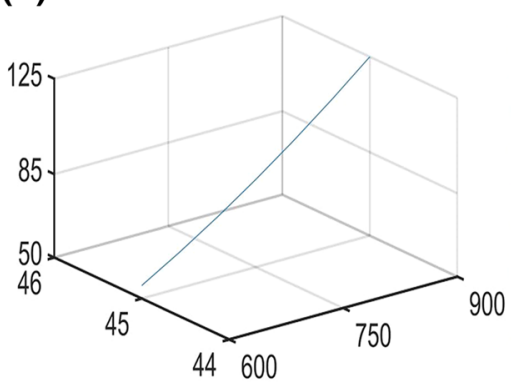

(d)

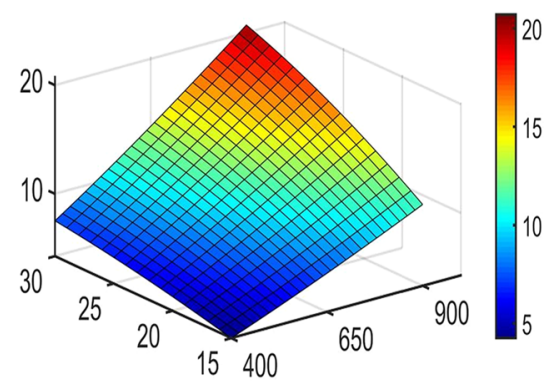

(e)

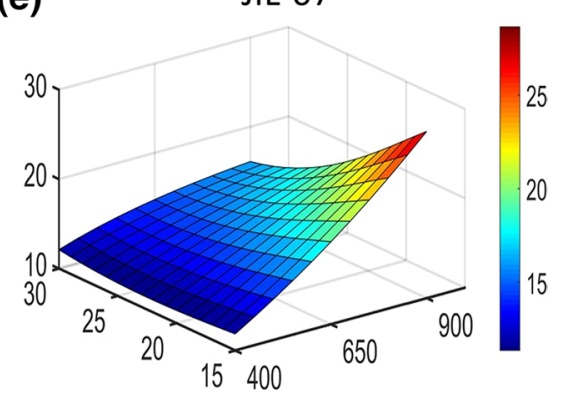

(c)

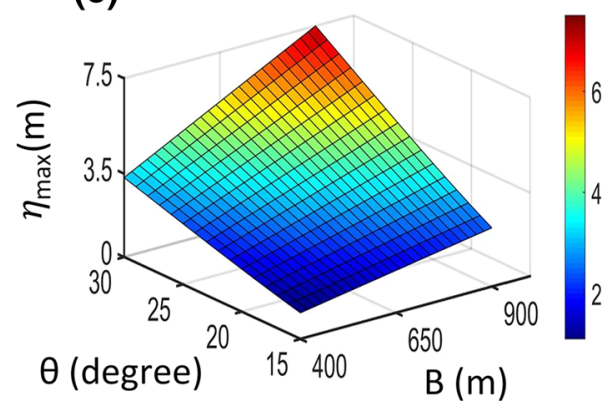

a) $\gamma_{s}=2.1 ; d=175 \mathrm{~m}$

b) $x_{s}=2.1 ; \quad \theta=45.0^{\circ} ; d / b \approx 0.87$

c) $\gamma_{s}=n / a ; d=175 \mathrm{~m} ; \quad T=40 \mathrm{~m}$

d) $\gamma_{\mathrm{s}}=2.1 ; \quad d=175 \mathrm{~m} ; \quad T=40 \mathrm{~m}$

e) $\gamma_{s}=2.1 ; d=175 \mathrm{~m} ; \quad T=40 \mathrm{~m}$

Fig. 6 Effects of slide length $(B)$ and slope angle $(\theta)$ on the maximum initial landslide wave amplitude resulting from equations of Harbitz and Pedersen (1992) (HRB-92), Watts (1998) (WTS-98), Watts et al. (2003) (WTS-03), Watts et al. (2005) (WTS-05) and Jilani and Ataie-Ashtiani (2008) (JIL-07). In each panel, while two slide parameters are varied, the other parameters are kept constant. The values of the constant slide parameters are shown at the bottom-right corner of the figure for each panel.' For panel 'c', the parameter $\gamma_{s}$ does not exist in the equation by Watts et al. (2003); thus, we put 'n/a' here which stands for 'not applicable'

mass failures could cause deadly tsunamis (Tappin et al. 2008). Based on the existing knowledge, the maximum initial wave amplitudes were reported as $11 \mathrm{~m}$ and $16 \mathrm{~m}$ by Heinrich et al. (2001) and Synolakis et al. (2002), respectively. Therefore, we considered a value in the range of 11-16 $\mathrm{m}$ as the observed initial wave amplitude for the PNG event (Table 4, first row; Fig. 8b, pink lines). The initial slide parameters are based on those shown in Table 1. The results of the predictions are given in Table 4 and Fig. $8 \mathrm{~b}$ 
(a)

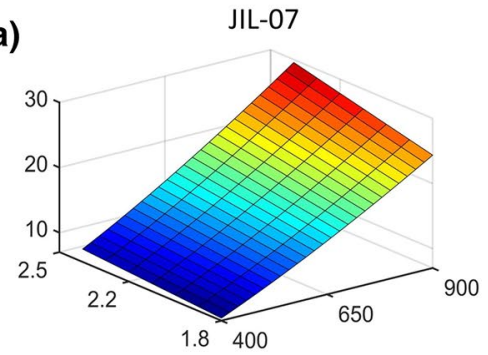

(b)

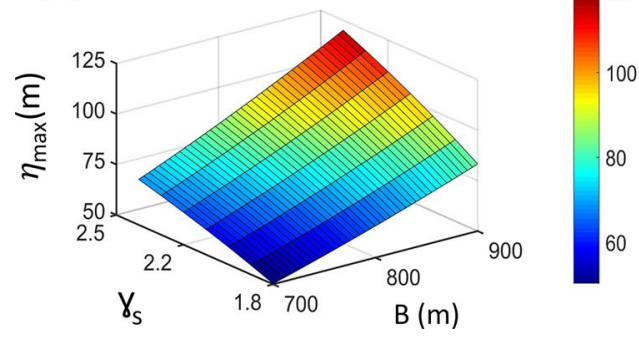

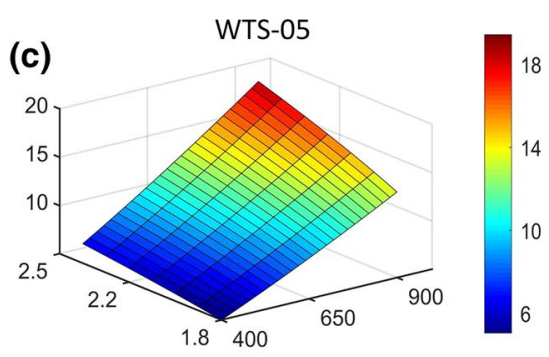

a) $\theta=22.5^{\circ} ; \mathrm{d}=175 \mathrm{~m} ; \mathrm{T}=40 \mathrm{~m}$

b) $\theta=45.0^{\circ} ; d / b \approx 0.87$

c) $\theta=22.5^{\circ} ; \mathrm{d}=175 \mathrm{~m} ; \mathrm{T}=40 \mathrm{~m}$

Fig. 7 Effects of slide specific gravity $\left(\gamma_{s}\right)$ and slide length $(B)$ on the maximum initial landslide wave amplitude resulting from equations of Watts et al. (2005) (WTS-05), Watts (1998) (WTS-98) and Jilani and Ataie-Ashtiani (2008) (JIL-98). In each panel, while two slide parameters are varied, the other parameters are kept constant. The values of the constant slide parameters are shown at the bottom-right corner of the figure for each panel

(blue bars and yellow circles). A wide range of $1.2-17397.5 \mathrm{~m}$ is obtained from various equations (Table 4). The representative initial landslide parameters yield wave amplitude estimates of 3.7-6746.0 m (yellow circles in Fig. 8b). According to Fig. 8b, the equation WTS-03 yields the best prediction among the existing equations.

In summary, the two benchmark tests reveal that the estimates of initial landslide waves made by different equations are divided by a few orders of magnitude. The predictions for the smaller-size event (i.e. 1994 Skagway) appear to be more accurate than those made for the larger event (i.e. 1998 PNG). The reason that many existing equations fail in the accurate prediction of larger-scale events could be due to the lack of enough physical studies in this field, in particular, the absence of enough large-scale landslide investigations. The equation by WTS-03 shows better performance in predicting the maximum initial wave amplitudes for both case studies. However, WTS-03's equation requires several initial landslide parameters which may make it difficult to use this equation for events with limited information. Some models (e.g. MRT-03) show a good performance in predicting the 1994 event (Fig. 8a) but fail for the 1998 case (Fig. 8b); this could be attributed to the rather complex physics of submarine landslide failures and the limitations of the existing equations. Our results may reveal the importance of large-scale or field-scale laboratory experiments on landslide tsunamis; such tests are costly, but it appears they are necessary to advance the knowledge of landslide tsunamis. 
Table 3 Maximum and minimum observed (first row) and predicted (later rows) initial wave amplitudes for the 1994 Skagway landslide tsunami

\begin{tabular}{|c|c|c|c|c|c|}
\hline & $\begin{array}{l}\text { Predictive } \\
\text { equations }^{\mathrm{a}}\end{array}$ & $\begin{array}{l}\text { Highest possible } \\
\text { value of } \eta_{\max }(m)\end{array}$ & $\begin{array}{l}\text { Lowest possible } \\
\text { value of } \eta_{\max }(m)\end{array}$ & $\begin{array}{l}\text { Range of param- } \\
\text { eters }\end{array}$ & $\begin{array}{l}\text { Repre- } \\
\text { sentative } \\
\text { value }(\mathrm{m})\end{array}$ \\
\hline $\begin{array}{l}\text { Real observed } \\
\text { value }^{\text {b }}\end{array}$ & N/A & 2.1 & 1.0 & N/A & N/A \\
\hline \multirow[t]{7}{*}{$\begin{array}{l}\text { Predicted by equa- } \\
\text { tions }\end{array}$} & HRB-92 & 6.4 & 1.4 & $\begin{array}{l}B=100-600 \mathrm{~m} \\
w=330-390 \mathrm{~m} \\
\gamma_{s}=1.75-1.85 \\
T=10-20 \mathrm{~m} \\
\theta=9-26\left(^{\circ}\right)\end{array}$ & 3.5 \\
\hline & WTS-98 & 686.5 & 0.9 & $\begin{array}{l}B=100-600 \mathrm{~m} \\
d=26-155 \mathrm{~m} \\
\gamma_{s}=1.75-1.85 \\
\theta=9-26\left(^{\circ}\right)\end{array}$ & 19.4 \\
\hline & GRL-02 & 6.0 & 2.1 & $\begin{array}{l}B=100-600 \mathrm{~m} \\
w=330-390 \mathrm{~m}\end{array}$ & 3.1 \\
\hline & MRT-03 & 1.8 & 0.1 & $\begin{array}{l}B=100-600 \mathrm{~m} \\
w=330-390 \mathrm{~m} \\
T=10-20 \mathrm{~m}\end{array}$ & 0.8 \\
\hline & WTS-03 & 13.7 & 0.03 & $\begin{array}{l}B=100-600 \mathrm{~m} \\
d=26-155 \mathrm{~m} \\
T=10-20 \mathrm{~m} \\
\theta=9-26\left(^{\circ}\right)\end{array}$ & 1.6 \\
\hline & WTS-05 & 54.6 & 0.1 & $\begin{array}{l}B=100-600 \mathrm{~m} \\
d=26-155 \mathrm{~m} \\
\gamma_{s}=1.75-1.85 \\
T=10-20 \mathrm{~m} \\
\theta=9-26\left(^{\circ}\right)\end{array}$ & 1.3 \\
\hline & JIL-07 & 121.7 & 0.4 & $\begin{array}{l}B=100-600 \mathrm{~m} \\
d=26-155 \mathrm{~m} \\
\gamma_{s}=1.75-1.85 \\
T=10-20 \mathrm{~m} \\
\theta=9-26\left(^{\circ}\right)\end{array}$ & 2.9 \\
\hline
\end{tabular}

a Abbreviations are: Harbitz and Pedersen (1992), HRB-92; Watts (1998), WTS-98; Grilli et al. (2002), GRL-02; Murty (2003), MRT-03; Watts et al. (2003), WTS-03; Watts et al. (2005), WTS-05; Jilani and Ataie-Ashtiani (2008), JIL-07

${ }^{\mathrm{b}}$ The real observed values are based on Kulikov et al. (1996) and Watts et al. (2005)

${ }^{\mathrm{c}}$ It is noted that the equation for Watts (1998) (WTS-98) is valid for a single value of $\theta=45^{\circ}$, whereas the slope angle for the 1994 Skagway failure was $9^{\circ}-26^{\circ}$ (Campbell 1995; Kulikov et al. 1996) 
(a) The 1998 PNG event

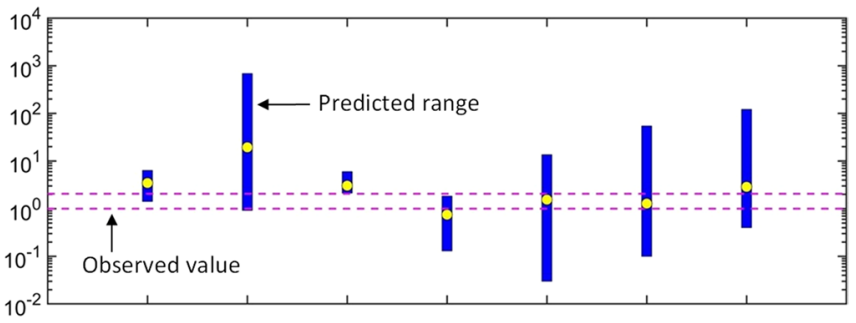

(b) The 1994 Skagway event

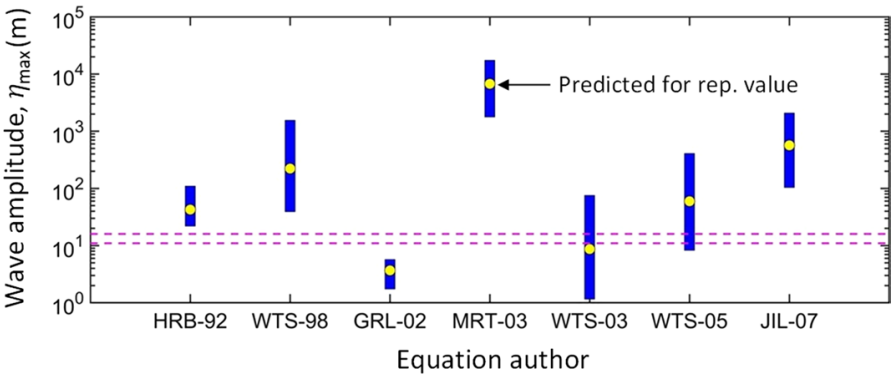

Fig. 8 Predictions made by various equations for the maximum initial landslide wave amplitudes of the 1994 Skagway (a) and 1998 PNG (b) tsunamis. The blue bars are the range of values predicted by different equations; the yellow circles are the prediction made by various equations only for the representative slide parameters (see Table 1). The dashed pink lines are the real observed values for initial tsunami amplitudes. Abbreviations are: Harbitz and Pedersen (1992), HRB-92; Watts (1998), WTS-98; Grilli et al. (2002), GRL-02; Murty (2003), MRT-03; Watts et al. (2003), WTS-03; Watts et al. (2005), WTS-05; Jilani and Ataie-Ashtiani (2008), JIL-07. In this figure, 'rep.' stands for representative

\section{A new empirical equation for the maximum initial wave amplitude of submarine landslide tsunamis}

The sensitivity analysis of landslide parameters revealed that slide volume $(V)$ and initial submergence depth $(d)$ are among the most sensitive parameters for predicting the initial wave amplitude generated by a submarine landslide (Figs. 3, 4). Based on our sensitivity analysis, the maximum initial wave amplitude $\left(\eta_{\max }\right)$ is directly related to slide volume (i.e. $V=B \times w \times T$ ) but is inversely correlated with initial slide submergence (Fig. 3). Existing data available in the literature on tsunami events induced by submarine landslides (Table 5; Fig. 9) were used as the observational data for obtaining a new predictive equation. The genetic algorithm, in MATLAB (Mathworks 2019), was employed for deriving the following regression equation:

$$
\eta_{\max }=50.67\left(\frac{V}{d}\right)^{0.34}
$$

where the slide volume $(V)$ is in $\mathrm{Km}^{3}$, the initial slide submergence $(d)$ is in metres, and $\eta_{\max }$ is the maximum initial amplitude in metres. The two sides of Eq. (6) do not dimensionally agree because our purpose is to fit an equation to the existing field data, as is commonly done in the literature (e.g. equations by MRT-03 and GRL-02; Table 2). We note that the equation was fitted on some of the data listed in Table 5 (i.e. events of 1979 France; 1975 Canada; 1999 Turkey; 1994 PNG and 1994 USA). The new equation (Eq. 6) 
Table 4 Maximum and minimum observed (first row) and predicted (later rows) initial wave amplitudes for the 1998 PNG landslide tsunami

Predictive Highest possible Lowest possible Range of param- Representaequations $^{\mathrm{a}} \quad$ value of $\eta_{\max }(\mathrm{m})$ value of $\eta_{\max }(\mathrm{m})$ eters tive value

(m)

\begin{tabular}{|c|c|c|c|c|c|}
\hline $\begin{array}{l}\text { Real observed } \\
\text { value }^{\text {b }}\end{array}$ & N/A & 16.0 & 11.0 & $\begin{array}{l}B=3000-7000 \mathrm{~m} \\
w=3000-7000 \mathrm{~m} \\
\gamma_{s}=1.9-2.2 \\
T=500-900 \mathrm{~m} \\
\theta=5-15\left(^{\circ}\right)\end{array}$ & N/A \\
\hline \multirow{7}{*}{$\begin{array}{l}\text { Predicted by equa- } \\
\text { tions }\end{array}$} & HRB-92 & 110.0 & 21.9 & $B=3000-7000 \mathrm{~m}$ & 42.7 \\
\hline & WTS-98c & 1553.8 & 39.2 & $\begin{array}{l}B=3000-7000 \mathrm{~m} \\
d=1000-2000 \mathrm{~m} \\
\gamma_{s}=1.9-2.2 \\
\theta=5-15\left(^{\circ}\right)\end{array}$ & 222.5 \\
\hline & GRL-02 & 5.7 & 1.7 & $\begin{array}{l}B=3000-7000 \mathrm{~m} \\
w=3000-7000 \mathrm{~m}\end{array}$ & 3.7 \\
\hline & MRT-03 & 17397.5 & 1775.3 & $\begin{array}{l}B=3000-7000 \mathrm{~m} \\
w=3000-7000 \mathrm{~m} \\
T=500-900 \mathrm{~m}\end{array}$ & 6746.0 \\
\hline & WTS-03 & 75.5 & 1.2 & $\begin{array}{l}B=3000-7000 \mathrm{~m} \\
d=1000-2000 \mathrm{~m} \\
T=500-900 \mathrm{~m} \\
\theta=5-15\left(^{\circ}\right)\end{array}$ & 8.7 \\
\hline & WTS-05 & 408.4 & 8.3 & $\begin{array}{l}B=3000-7000 \mathrm{~m} \\
d=1000-2000 \mathrm{~m} \\
\gamma_{s}=1.9-2.2 \\
T=500-900 \mathrm{~m} \\
\theta=5-15\left(^{\circ}\right)\end{array}$ & 59.7 \\
\hline & JIL-07 & 2081.5 & 103.8 & $\begin{array}{l}B=3000-7000 \mathrm{~m} \\
d=1000-2000 \mathrm{~m} \\
\gamma_{s}=1.9-2.2 \\
T=500-900 \mathrm{~m} \\
\theta=5-15\left(^{\circ}\right)\end{array}$ & 567.8 \\
\hline
\end{tabular}

a Abbreviations are: Harbitz and Pedersen (1992), HRB-92; Watts (1998), WTS-98; Grilli et al. (2002), GRL-02; Murty (2003), MRT-03; Watts et al. (2003), WTS-03; Watts et al. (2005), WTS-05; Jilani and Ataie-Ashtiani (2008), JIL-07

${ }^{\mathrm{b}}$ The real observed values are based on Synolakis et al. (2002) and Heinrich et al. (2001)

${ }^{\mathrm{c}}$ It is noted that the equation for Watts (1998) (WTS-98) is valid for a single value of $\theta=45^{\circ}$, whereas the slope angle for the 1998 PNG failure was $5-15^{\circ}$ (Heinrich et al. 2001 Synolakis et al. 2002; Heidarzadeh and Satake 2015) 


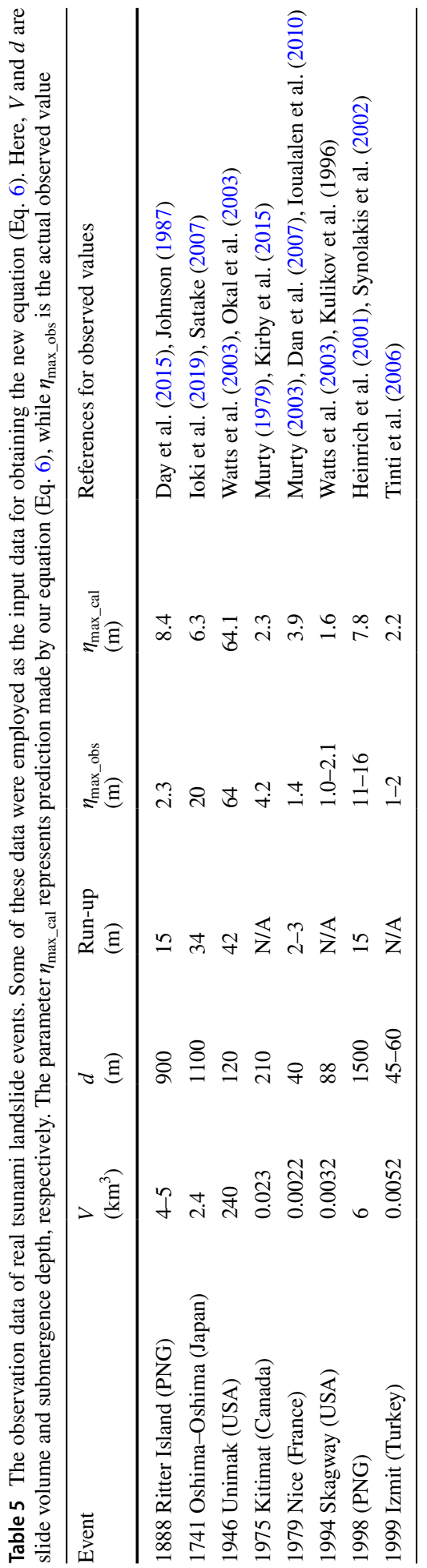




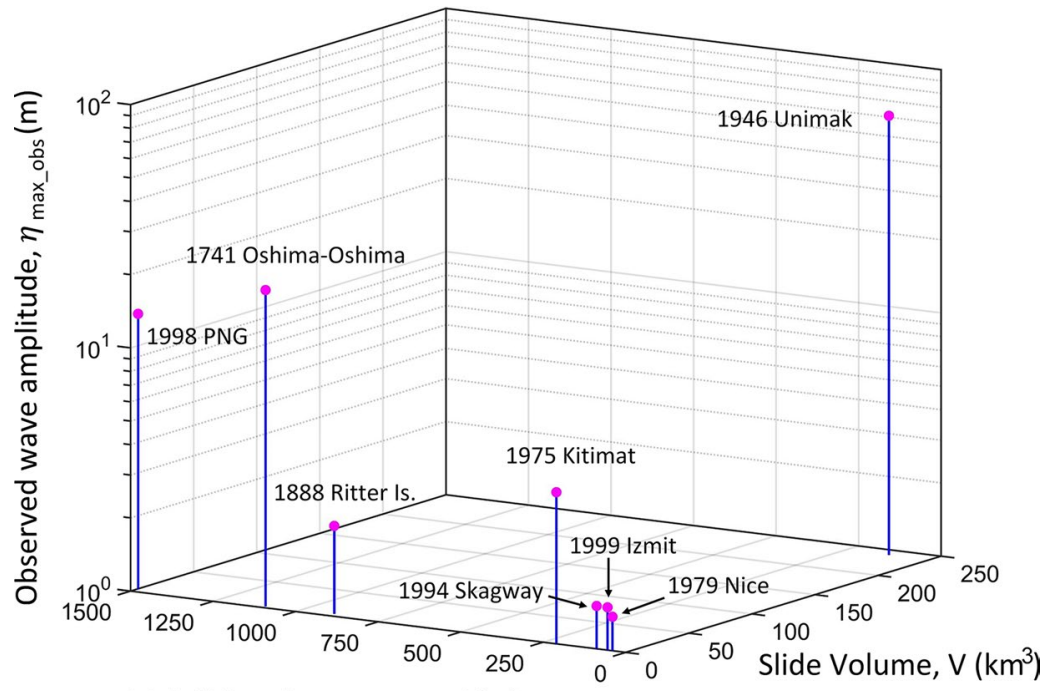

Initial slide submergence, $d(m)$

Fig. 9 A 3D projection of the maximum initial amplitudes of observed landslide events $\left(\eta_{\max \_o b s}\right)$ based on their volumes $(V)$ and submergence depths $(d)$. The references for these data are given in Table 5

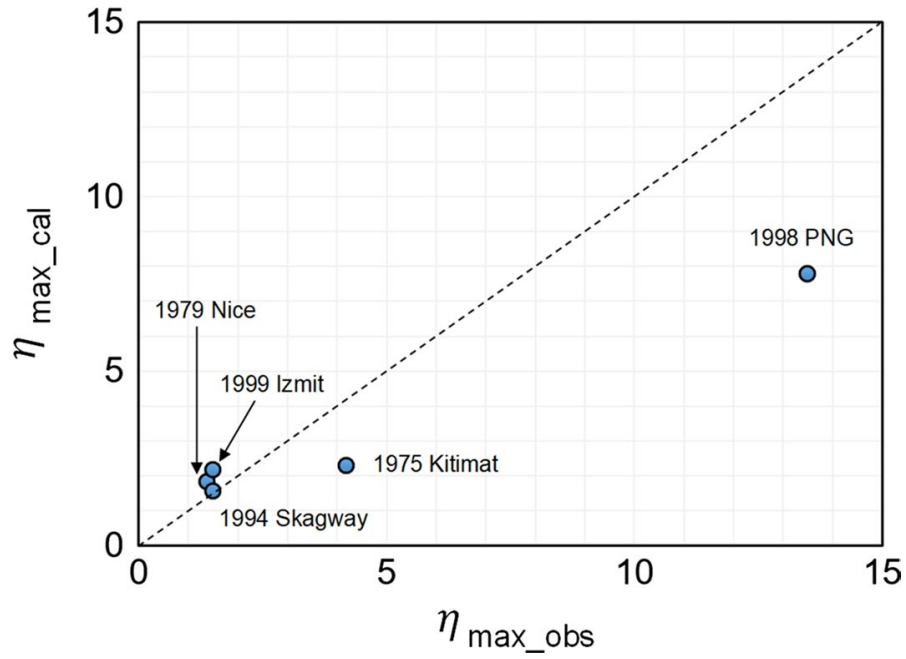

Fig. 10 The observed maximum initial wave amplitude $\left(\eta_{\max \_ \text {obs }}\right)$ versus the calculated values $\left(\eta_{\text {max_cal }}\right)$ using our proposed equation (Eq. 6)

provides a preliminary prediction of the initial wave amplitude for potential submarine landslides for cases with minimum available landslide information. The linear regression for the new proposed equation yields an acceptable correlation coefficient of $R^{2}=0.92$. Table 5 and Fig. 10 compare the observed wave amplitudes $\left(\eta_{\text {max } \_ \text {obs }}\right)$ with those predicted by Eq. (6) $\left(\eta_{\text {max_cal }}\right)$. By applying our proposed equation to the two benchmark tests of the 1994 Skagway and 1998 PNG tsunamis, we obtained initial wave amplitudes of $1.6 \mathrm{~m}$ 
Table 6 The calculated maximum initial wave amplitude based on our proposed equation $\left(\eta_{\text {max_cal }}\right)$ for potential submarine landslides located in Western Thailand (Andaman Sea) and Lake Ohrid (Macedonia/ Albania). Here, $V$ and $d$ are slide volume and submergence depth, respectively

\begin{tabular}{lccc}
\hline Location of potential submarine landslide & $V\left(\mathrm{~km}^{3}\right)$ & $d(\mathrm{~m})$ & $\eta_{\text {max_cal }}(\mathrm{m})$ \\
\hline Andaman Sea, Western Thailand & $11.1^{*}$ & $880^{*}$ & 11.4 \\
& $0.07^{* *}$ & $1100^{* *}$ & 1.9 \\
Lake Ohrid, Macedonia/Albania $^{* * *}$ & 0.063 & 120 & 3.9 \\
\hline
\end{tabular}

*Landslide data based on scenario A in Schwab et al. (2014)

** Landslide data based on scenario B in Schwab et al. (2014)

${ }^{* * * *}$ Landslide data from Lindhorst et al. (2014)

and $7.8 \mathrm{~m}$ for these events, respectively, which are fairly close to the observed amplitudes (Table 5, column 6).

Here, we apply our Eq. (6) to two cases of submarine landslides to predict maximum initial wave amplitudes. Seismic and bathymetric surveys of submarine features provide valuable information for locating potential submarine landslides (e.g. Fu et al. 2017). As examples of previous geophysical investigations of the seafloor, Schwab et al. (2014) and Lindhorst et al. (2014) located potential submarine landslides offshore western Thailand (Andaman Sea) and inside Lake Ohrid (Macedonia/Albania), respectively. We benefit from landslide scenarios A and B of Schwab et al. (2014) for the Andaman Sea with respective volumes of 11.1 and $0.07 \mathrm{~km}^{3}$ at water depths of 880 and $1100 \mathrm{~m}$, respectively (Table 6). For the lake Ohrid, Lindhorst et al. (2014) reported a slide with a volume of $0.063 \mathrm{~km}^{3}$ at a depth of $120 \mathrm{~m}$. Our new proposed equation (Eq. 6) is applied to estimate the maximum initial wave amplitudes which resulted in predicated initial wave amplitudes of 11.4 and $1.9 \mathrm{~m}$ for the two landslides scenarios A and B of the Andaman Sea and $3.9 \mathrm{~m}$ for the Lake Ohrid (Table 6).

\section{Conclusion}

Existing equations for the prediction of maximum initial submarine landslide-generated waves were examined through sensitivity analyses and benchmark tests. The main findings are as follows:

- Among all involved parameters in the existing predictive equations, slide volume $(V)$ appears in most equations, thus emphasising its importance in estimating the maximum initial wave amplitude generated by submarine landslides.

- The predictions of wave amplitude through existing equations are divided by a few orders of magnitude. In particular, the values range from 0.03 to $686.5 \mathrm{~m}$ for the prediction of the maximum initial amplitude of the 1994 Skagway and from 3.7 to $6746.0 \mathrm{~m}$ for the 1998 Papua New Guinea (PNG) tsunamis. The observed amplitudes for the two aforesaid events are in the ranges of 1.0-2.1 $\mathrm{m}$ and 11-16 $\mathrm{m}$, respectively.

- By applying the existing predictive equations to the two cases of 1994 Skagway and 1998 PNG landslide tsunamis, we witnessed a better agreement between the observed and predicted maximum initial wave amplitudes for the small-scale landslide tsunami 
(i.e. 1994 Skagway). For the large-scale tsunami (i.e. 1998 PNG), the predictions are scattered in a wider range. This may emphasis the essentiality of conducting large-scale or field-scale laboratory experiments on landslide-induced tsunamis.

- We put forward a new equation by benefiting from the existing information from previous real cases of submarine landslide tsunamis: $\eta_{\max }=50.67\left(\frac{V}{d}\right)^{0.34}$, where $V$ is slide volume $\left(\mathrm{km}^{3}\right), d$ is initial submergence depth $(\mathrm{m})$, and $\eta_{\max }$ is in metres. This new equation resulted in wave amplitudes of $1.6 \mathrm{~m}$ and $7.8 \mathrm{~m}$ for the 1994 Skagway and 1998 PNG tsunamis, respectively, indicating fair agreement with real observed values for these tsunamis.

Acknowledgements We are grateful to Prof Alexander Rabinovich (Institute of Ocean Sciences, Fisheries and Oceans Canada, Sidney, Canada) for providing the observed tide gauge waveform of the 1994 Skagway tsunami. We sincerely thank Professor James Goff (the Editor-in-Chief) and two anonymous reviewers for their constructive review comments which greatly helped to improve this article. MH is funded by the Royal Society, the United Kingdom, under Grant Number CHLIR1\180173.

\section{Compliance with ethical standards}

Conflict of interest The authors declare that they have no competing interests. The data and material used in this research are available in the body of the article.

Open Access This article is licensed under a Creative Commons Attribution 4.0 International License, which permits use, sharing, adaptation, distribution and reproduction in any medium or format, as long as you give appropriate credit to the original author(s) and the source, provide a link to the Creative Commons licence, and indicate if changes were made. The images or other third party material in this article are included in the article's Creative Commons licence, unless indicated otherwise in a credit line to the material. If material is not included in the article's Creative Commons licence and your intended use is not permitted by statutory regulation or exceeds the permitted use, you will need to obtain permission directly from the copyright holder. To view a copy of this licence, visit http://creativecommons.org/licenses/by/4.0/.

\section{References}

Assier-Rzadkieaicz S, Heinrich P, Sabatier PC, Savoye B, Bourillet JF (2000) Numerical modelling of a landslide-generated tsunami: the 1979 Nice event. Pure appl Geophys 157(10):1707-1727

Campbell B (1995) Report of a seafloor instability at Skagway, Alaska, 3 November 1994. Hancock Drive, Anchorage

Campbell B, Nottingham D (1999) Anatomy of a landslide created tsunami at Skagway, Alaska. Sci Tsunami Hazards 17(1):19-48

Dan G, Sultan N, Savoye B (2007) The 1979 Nice harbour catastrophe revisited: trigger mechanism inferred from geotechnical measurements and numerical modelling. Mar Geol 245(1):40-64

Day S, Llanes P, Silver E, Hoffmann G, Ward S, Driscoll N (2015) Submarine landslide deposits of the historical lateral collapse of Ritter Island, Papua New Guinea. Mar Petrol Geol 67:419-438

Fine IV, Rabinovich A, Bornhold B, Thomson R, Kulikov E (2005) The Grand Banks landslide-generated tsunami of November 18, 1929: preliminary analysis and numerical modeling. Mar Geol 215(1):45-57

Fu L, Heidarzadeh M, Cukur D, Chiocci FL, Ridente D, Gross F, Bialas J, Krastel S (2017) Tsunamigenic potential of a newly discovered active fault zone in the outer Messina Strait, Southern Italy. Geophys Res Lett 44(5):2427-2435

Gennesseaux M (1980) Les glissements sous-marins de la pente continentale niçoise et la rupture de câbles en mer Ligure (Méditerranée occidentale). C R Acad Sci D 290(14):959-962

Grilli ST, Watts P (2005) Tsunami generation by submarine mass failure. I: modeling, experimental validation, and sensitivity analyses. J Waterw Port Coast Ocean Eng 131(6):283-297 
Grilli ST, Vogelmann S, Watts P (2002) Development of a 3D numerical wave tank for modelling tsunami generation by underwater landslides. Eng Anal Bound Elem 26(4):301-313

Harbitz CB (1992) Model simulations of tsunamis generated by the Storegga slides. Mar Geol 105(1):1-21

Harbitz CB, Pedersen G (1992). Model theory and analytical solutions for large water waves due to landslides. Preprint series. Mech Appl Math NBN 23418

Heidarzadeh M, Satake K (2015) Source properties of the 17 July 1998 Papua New Guinea tsunami based on tide gauge records. Geophys J Int 202(1):361-369

Heidarzadeh M, Krastel S, Yalciner AC (2014) The state-of-the-art numerical tools for modeling landslide Tsunamis: a short review. In: Submarine mass movements and their consequences. Chapter 43, 483495. Springer, Berlin, ISBN: 978-3-319-00971-1

Heidarzadeh M, Ishibe T, Sandanbata O, Muhari A, Wijanarto AB (2020) Numerical modeling of the subaerial landslide source of the 22 December 2018 Anak Krakatoa volcanic tsunami, Indonesia. Ocean Eng. https://doi.org/10.1016/j.oceaneng.2019.106733

Heinrich P (1992) Nonlinear water waves generated by submarine and aerial landslides. J Waterway Port Coast Ocean Eng 118(3):249-266

Heinrich P, Piatanesi A, Hebert H (2001) Numerical modelling of tsunami generation and propagation from submarine slumps: the 1998 Papua New Guinea event. Geophys J Int 145(1):97-111

Ioki K, Tanioka Y, Yanagisawa H, Kawakami G (2019) Numerical simulation of the landslide and Tsunami Due to the 1741 Oshima-Oshima Eruption in Hokkaido, Japan. J Geophys Res 124(2):1991-2002

Ioualalen M, Migeon S, Sardoux O (2010) Landslide tsunami vulnerability in the Ligurian Sea: case study of the 1979 October 16 Nice international airport submarine landslide and of identified geological mass failures. Geophys J Int 181(2):724-740

Iquebal MA, Himadri G (2012) Genetic algorithm optimization technique for linear regression models with heteroscedastic errors. Indian J Agr Sci 82(5):422-425

Jilani A, Ataie-Ashtiani B (2008) Estimation of near-field characteristics of tsunami generation by submarine landslide. Ocean Eng 35(5):545-557

Johnson RW (1987) Large-scale volcanic cone collapse: the 1888 slope failure of Ritter volcano, and other examples from Papua New Guinea. Bull Volcanol 49(5):669-679

Kirby JT, Shi F, Nicolsky D, Ma G, Misra S, Rao P (2015) The 1975 Kitimat Landslide Tsunami: validation and comparative testing of modeling strategies. In: Coastal structures and solutions to coastal disasters, Reston, VA

Kulikov EA, Rabinovich AB, Thomson RE, Bornhold BD (1996) The landslide tsunami of 3 November 1994, Skagway harbour, Alaska. J Geophys Res 101(C3):6609-6615

Lindhorst K, Krastel S, Papenberg C, Heidarzadeh M (2014) Modelling submarine landslide-generated waves in Lake Ohrid, Macedonia/Albania. In: Submarine mass movements and their consequences. Springer, Berlin

Liu PF, Wu TR, Raichlen F, Synolakis CE, Borrero JC (2005) Runup and rundown generated by threedimensional sliding masses. J Fluid Mech 536:107-144

Lynett PJ, Borrero JC, Liu PL, Synolakis CE (2003) Field survey and numerical simulations: a review of the 1998 Papua New Guinea tsunami. Pure appl Geophys 160:2119-2146

Mathworks (2019) MATLAB user manual. The Math Works Inc, MA, p 282

Murty TS (1979) Submarine slide-generated water waves in Kitimat Inlet, British Columbia. J Geophys Res 84(C12):7777-7779

Murty TS (2003) Tsunami wave height dependence on landslide volume. Pure appl Geophys 160(10-11):2147-2153

Okal EA, Plafker G, Synolakis CE, Borrero JC (2003) Near-field survey of the 1946 Aleutian tsunami on Unimak and Sanak Islands. Bull Seismol Soc Am 93(3):1226-1234

Rabinovich AB, Thomson RE, Kulikov EA, Bornhold BD, Fine IV (1999) The landslide-generated tsunami of November 3, 1994 in Skagway Harbor, Alaska: a case study. Geophys Res Lett 26(19):3009-3012

Satake K (2007) Volcanic origin of the 1741 Oshima-Oshima tsunami in the Japan Sea. Earth Planets Space 59(5):381-390

Satake K, Kato Y (2001) The 1741 Oshima-Oshima eruption: extent and volume of submarine debris avalanche. Geophys Res Lett 28(3):427-430

Schwab J, Krastel S, Heidarzadeh M, Brune S (2014) Modeling of potential landslide Tsunami hazards off Western Thailand (Andaman Sea). In: Submarine mass movements and their consequences. Springer, Berlin

Sultan N, Cochonat P, Canals M, Cattaneo A, Dennielou B, Haflidason H, Laberg JS, Long D, Mienert J, Trincardi F, Urgeles R (2004) Triggering mechanisms of slope instability processes and sediment failures on continental margins: a geotechnical approach. Mar Geol 213(1):291-321 
Synolakis CE, Bardet JP, Borrero JC, Davies HL, Okal EA, Silver EA, Sweet S, Tappin DR (2002) The slump origin of the 1998 Papua New Guinea tsunami. Proc R Soc Lond A 458(2020):763-789

Tappin DR, Watts P, Grilli ST (2008) The Papua New Guinea tsunami of 17 July 1998: anatomy of a catastrophic event. Nat Hazard Earth Syst 8(2):243-266

Tinti S, Armigliato A, Manucci A, Pagnoni G, Zaniboni F, Yalçiner AC, Altinok Y (2006) The generating mechanisms of the August 17, 1999 Izmit bay (Turkey) tsunami: regional (tectonic) and local (mass instabilities) causes. Mar Geol 225(1):311-330

Watts P (1998) Wave maker curves for tsunamis generated by underwater landslides. J Waterway Port Cost Ocean Eng 124(3):127-137

Watts P, Grilli ST, Kirby JT, Fryer GJ, Tappin DR (2003) Landslide tsunami case studies using a Boussinesq model and a fully nonlinear tsunami generation model. Nat Hazards Earth Sys Sci 3(5):391-402

Watts P, Grilli ST, Tappin DR, Fryer GJ (2005) Tsunami generation by submarine mass failure. II: predictive equations and case studies. J Waterway Port Coast Ocean Eng 131(6):298-310

Wiegel RL (1955) Laboratory studies of gravity waves generated by the movement of a submerged body. EOS Trans AGU 36(5):759-774

Yalciner AC, Synolakis C, Borrero J, Altinok Y, Watts P, Imamura F, Kuran U, Ersoy S, Kanoglu U, Tinti S (1999) Tsunami generation in Izmit Bay by the 1999 Izmit earthquake. In: Proceedings of conference on the 1999 Kocaeli Earthquake Istanbul Technical University

Yalciner AC, Zaytsev A, Aytore B, Insel I, Heidarzadeh M, Kian R, Imamura F (2014) A possible submarine landslide and associated Tsunami at the Northwest Nile Delta, Mediterranean Sea. Oceanography 27(2):68-75

Publisher's Note Springer Nature remains neutral with regard to jurisdictional claims in published maps and institutional affiliations. 